\title{
A LITERATURE REVIEW ON INTERNAL CURING OF CONCRETE
}

\author{
Sowjanya G V \\ Department of Civil \\ Sri Siddhartha Institute of Technology, \\ Tumkuru, India
}

\author{
Dr. Anadinni S B \\ Department of Civil \\ Presidency University \\ Bangluru, India
}

\author{
Dr Mahadevaiah T \\ Department of Civil \\ BGS Institute of Technology \\ B G Nagar, India
}

\begin{abstract}
Effective curing imparts strength and durability to concrete. According to American Concrete Institute 308 code "internal curing is a process by which the hydration of cement occurs due to availability of additional internal water that may results complete process of hydration". Traditionally, curing of concrete means creating conditions such that to prevent dissipation of water from the surface that is curing occurs from "outside to inside". However, internal curing happens from "inside to outside". Internal curing is also designated as self-curing. Light weight aggregates, super absorbent polymers, polyethylene glycol etc are the most commonly used materials for self-curing
\end{abstract}

Keywords - Internal Curing, Poly Ethylene Glycol, Light Weight Aggregate

\section{INTRODUCTION}

Curing of concrete should be done properly in order achieve strength and durability requirements of the concrete. To accomplish this, external curing is done after mixing, placing, and finishing in conventional concrete. For efficient hydration process of cement and decreased self-desiccation, internal curing is adopted which provides additional moisture in concrete. Internal curing plays a significant part in creating the microstructure and concrete pore structure.

Internally cured concrete is a special kind of concrete, it is important in places where insufficient curing is done because of human carelessness, water scarcity, structures built in unapproachable terrain and due to the presence of high fluoride content. Different methods of external and internal curing aimed to maintain moisture content is shown in figure 1.

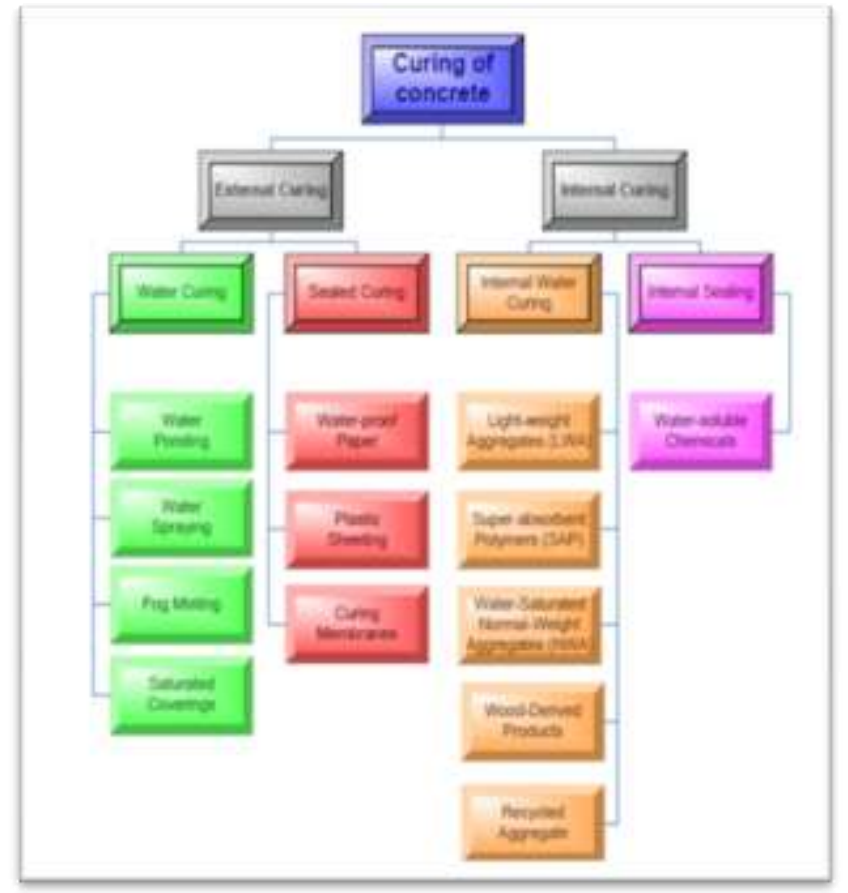

Fig 1: Different methods of external and internal curing

\section{A. Monitoring of Internal Curing}

Monitoring of internal curing can be done by adopting the following methods;

- Measuring loss of weight

- X-Ray microchromatography

- Compressive strength

- Initial surface absorption

- X-Ray powder diffraction

- Scanning electron microscope

- Change internal RH with time

- Thermogravimetry measurement 


\section{International Journal of Engineering Applied Sciences and Technology, 2019 Vol. 4, Issue 3, ISSN No. 2455-2143, Pages 182-185 \\ Published Online July 2019 in IJEAST (http://www.ijeast.com)}

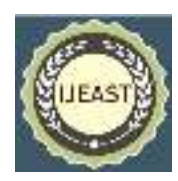

- NMR spectroscopy

- Water permeability

\section{MATERIALS}

The potential materials used for internal curing are stated below;

\section{A. Cement}

Cement is mainly made up of aluminates and silicates of calcium formed out of silica, calcium oxide, aluminum oxide and iron oxide.

\section{B. Light weight aggregates}

Lightweight aggregate is the general name of a group of aggregates with relative density lower than that of normal density aggregates (gravel, natural sand, and crushed stone), sometimes it is also called as low density aggregate.

\section{Polyethylene Glycol (PEG)}

Polyethylene Glycol is a polyether compound with various applications from medicine to manufacturing industry. PEG is also known as poly oxy ethylene (POE) or polyethylene oxide (PEO) depending on its molecular weight. The structure of PEG is expressed as $\mathrm{H}-(\mathrm{O}-\mathrm{CH} 2-\mathrm{CH} 2)_{\mathrm{n}}-\mathrm{OH}$.

\section{Super Absorbent Polymer (SAP)}

Superabsorbent polymer can retain and absorb extremely large amounts of a liquid relative to its own mass.Waterabsorbing polymers, which are categorized as hydro gels when cross-linked, absorb aqueous solutions through hydrogen bonding with water molecules. An SAP's ability to absorb water mainly depends on the ionic concentration of the aqueous solution.

\section{E. Wood Powder}

Wood powder is finely pulverized wood it has consistency fairly equal to sand or sawdust, but can vary considerably, with particles ranging in dimensions from a fine powder to roughly that of a grain of rice.

\section{LITERATURE REVIEW}

Gaston Espinoza et al. (2011) [10] main aim of this paper is to evaluate the effect of self curing under drying conditions with relatively high w/c concretes. Permeability, compressive strength and degree of hydration were estimated in both conventionally cured concrete and internally cured concrete. Results showed that under dry conditions, 30\% lesser permeability, 19\% higher compressive strength and $16 \%$ higher hydration when compared with conventionally cured concrete. It is concluded that the performance of w/c greater than 0.42 subjected to poor curing state can be improved by internal curing.
Mateusz Wyrzykowski et al. (2012) [16] water migration model was analysed by the author during internal curing by incorporating self curing agent (SAP). The SAP act as internal water reservoir, sand is distributed evenly in the concrete mix, during mixing it absorbs water and then it releases to the adjacent cement paste. Analysis showed internal curing can be achieved by adding SAP to concrete with less water-to-cement ratio.

JagannadhaKumar M V et al. (2012) [13] in the present study, strength properties were determined by conducted tests on M20 and M40 concrete mixes by adding PEG by weight of cement in a range varying from $0 \%$ to $2 \%$. It was found strength achieved is on par conventional curing. For M20 mix PEG 400 of $1 \%$ by weight of the cement was found to be ideal, while it is $0.5 \%$ for M40 mix for gaining maximum strength.

Ya Wei et al. (2014) [30] for the better utilization of internal curing method to attain durable concrete, this study explores the desorption properties and microstructure of expanded shale LWFAs and sintered fly ash. From the results it is concluded that if the particle size and the ratio of the LWFA particle/paste proximity is 1.1 , then $100 \%$ internal curing performs without autogenous shrinkage in concrete after 28 days.

Remya K M et al. (2015) [21] in this paper fine aggregates are partially substituted for pre soaked light weight aggregates and PEG-600 is added at a percentages of $0.5 \%, 1 \%, 1.5 \%$ and $2 \%$ of weight of the cement. For M20 concrete mix the compressive strength, flexural strength and split tensile strength of normally cured concrete at 3,7,14 and 28 days is compared with those of internally cured concrete. Results indicate that internally curing concrete with $20 \%$ fine aggregate substituted with light weight aggregate has maximum strength at an ideal value $1 \%$ PEG-600 by weight of the cement.

Bala Subramanian $K$ et al. (2015) [6] investigated on different grade of high strength concrete by considering $0.2 \%$ to $0.4 \%$ of Super Absorbent Polymer. In the experiment cement is replaced with silica fumes in the ranges of 5\%,10\% and $15 \%$ are studied. From the result it is concluded that high strength is developed in the cement with $10 \%$ replacement of silica fume, with $15 \%$ replacement of silca fume by weight of cement decreases rapid chloride permeability and with the increase of internal curing agent strength of the concrete also increases.

Magda I Mousa et al. (2015) [15] Strength properties of concrete containing polyethylene-glycol and Pre-soaked lightweight aggregate(LECA) as self-curing agents with different proportions and the addition of silica fume are 


\section{International Journal of Engineering Applied Sciences and Technology, 2019 Vol. 4, Issue 3, ISSN No. 2455-2143, Pages 182-185 \\ Published Online July 2019 in IJEAST (http://www.ijeast.com)}

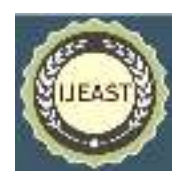

investigated in his paper. The author concluded that concrete with polyethylene-glycol attains maximum strength, than concrete with saturated LECA.

Iftikhar et al. (2015) [12] in this study fine aggregate is replaced by Pre-saturated saw dust at three replacement levels of 5,10 and $15 \%$ by mass respectively. Form the result it is found that the internally curing can be effective achieved when fine aggregate is replaced by $5 \%$ of saw dust.

Siddiqui Mohammed Junaid et al. (2016) [28] experimental work was carried out to investigate compressive strength of conventional cured concrete and it is compared with self cured concrete. PEG-400 in the rage of $1 \%, 2 \%$ and $3 \%$ is used as self curing agent. It is concluded that by adding $1 \%$ and $2 \%$ PEG-400 compressive strength of conventional concrete can be obtained in 7 days and 14 days respectively and it has also been observed during testing, conventionally cured concrete shows more cracks than internally cured concrete.

Bala Tripura Sundari D et al. (2016) [7] the scope of the research included the determination of Compressive strength and weight loss of M30 concrete casted with self-curing agent. $1 \%$ dosage of PEG 400 in indoor curing has higher compressive strength. Indoor cured concrete containing OPC has minimum loss of weight at $1 \%$ of PEG.

Sachin Julian Francis et al. (2017)[22] investigations are carried out to find the optimum percentage of substitute for fine aggregate by lightweight aggregate and optimum dosage of PEG400 by determining the strength properties of M30 grade concrete. The result showed that the $25 \%$ replacement of lightweight aggregate gives maximum split-tensile strength, compressive strength and modulus of rupture and one percent of PEG400 by weight of the cement was found to be ideal dose.

Mohammed Bilal et al. 2017) [18] experiment is carried on M50 grade concrete by adopting Solid Paraffin Wax (SPW) which is melted at $70^{\circ} \mathrm{C}$ of quantity varied between $0.1 \%, 1 \%$ and $2 \%$ by weight of the cement along with Super-Plasticizer is added to water. Result shows at $1 \%$ of SPW flexural, compression and split tensile strength test attains maximum value. From water retentivity test it is concluded that lesser weight loss occurs at $2 \%$ incorporation of SPW.

Jakkam Snehavi et al. (2018)[14] in this paper compressive and split tensile strength were carried on M30 grade of self curing concrete here fine aggregates are replaced by $50 \%$ of quarry dust and silica fume and fly ash are used as substituent for cement. Compared to silica fume results revealed compressive strength will be more when fly ash is used as substituent for cement.
MD Akhib K et al. (2018) [17] M65 grade of concrete is casted and it subjected to split tensile and compressive strength test for both conventional and internal curing conditions. From the obtained results it can be stated that polyethylene Glycol can be used as internal curing agent and also it is noticed 1\% of PEG 400 for M65 grade of concrete is optimum to get high strength.

Agalya C et al. (2018) [1] Experiment is carried on M20 concert by considering $2 \%$ of steel fibers and dosage of PEG 400 varied in the rage of $1 \%, 1.5 \%$ and $2 \%$. It is concluded that PEG-400 of $1.5 \%$ dose and steel fibers of $2 \%$ attains maximum flexural, split tensile and compressive Strength.

\section{CONCLUSIONS}

1. Light weight aggregates and internal curing agents have been used to achieve internal curing.

2. Internally cured concrete will be having more strength compare to normally cured concrete.

3. For maximum strength gain $1 \%$ of PEG-400 is found to be ideal dose.

4. Fine aggregates with $20 \%$ replaced by light weight aggregate will develop maximum strength at $1 \%$ of PEG600.

5. Curing can also be achieved by replacing fine aggregate partially with saw dust.

\section{REFERENCES}

[1] Agalya C and Dr Dhanalakshmi G , (2018), An experimental Study on Self Curing Concrete by using Steel Fiber and Polyethylene Glycol, InternationalResearch Journal of Engineering and Technology;, vol 5,(pp.2065-2069).

[2] Ata Olugbenga,( 2017) Effects of Varying Curing Age and Water/Cement Ratio on the Elastic properties of Laterized Concrete; Civil Engineering Dimension, Vol. 9, (pp.85-89).

[3] Ayangade J A, Alake O, and Wahab A B.( 2009), The Effects of Different Curing Methods on the Compressive Strength of Terracrete, Civil Engineering Dimension, Vol. 11, (pp.41-45).

[4] Azhagarsamy S \& Sundararaman S, (2016), A Study on Strength and Durability of Self Curing Concrete Using Polyethylene Glycol-400, International Journal of Research in Engineering and Technology, vol 6,(pp. 215-218).

[5] Bala Krishna J andRamavath Jaipal, (2017), Comparative and Experimental Study on Self Curing Concrete, International Journal of Research Sciences and Advanced Engineering, vol 2, (pp.118-129).

[6] Bala Subramanian K, Siva A, Swaminathan S, Arul M G and Ajin, ( 2015) Development of High Strength Self Curing Concrete Using Super Absorbing Polymer; International Journal of Civil, Environmental, Structural, Construction and Architectural Engineering,vol 9,(pp. 536-154).

[7]Bala Tripura Sundari D, Manikanta V and Aparna L, (2016), PEG (Poly Ethylene Glycol) as an internal Curing 


\section{International Journal of Engineering Applied Sciences and Technology, 2019 Vol. 4, Issue 3, ISSN No. 2455-2143, Pages 182-185 \\ Published Online July 2019 in IJEAST (http://www.ijeast.com)}

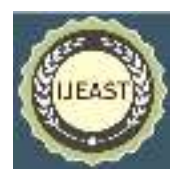

Agent in Ordinary Concrete, International Journal of Combined Research \& Development; vol 5, (pp.1103-1109).

[8]Bashandy A A , (2016) Self-curing Concrete under SulfateAttack, Archives of Civil Engineering,(pp.1-18).

[9]Basil M Joseph, (2016), Studies on Properties of SelfCuring Concrete Using Poly-Ethylene Glycol; IOSR Journalof Mechanical and CivilEngineering, (pp.12-17).

[10]Gaston Espinoza-Hijazin and Mauricio Lopez, (2010), Extending internal curing to concrete mixtures with W/C higher than 0.42, Construction and Building Materials@ Elsevier;,vol 25,(pp.1236-1242).

[11]Glory Joseph and Ramamurthy K , (2011), Autogenous Curing of Cold-Bonded Fly-Ash Aggregate Concrete, Journal of Materials in Civil Engineering @ ASCE, Vol. 23,(pp. 393401).

[12]Iftikhar, Azim, Bazid Khan, Shams-Ul-Islam, and Sikandar Hayat Sajid, (2015), Pre-saturated Sawdust as a source of Internal curing in high performance concrete; International Journal of Advanced Structures and Geotechnical Engineering, vol 4,(pp.109-113).

[13] Jagannadha Kumar M V, Srikanthand M and. Jagannadha Rao K, (2012), Strength Characteristics of self-Curing Concrete, International Journal of Research in Engineering and Technology, vol 1, (pp.51-57).

[14]Jakkam snehavi and Yashwanth A, ( 2018), Experimental Study on Self Curing Concrete with Replacement of Cement with Fly Ash \& Silica Fume and Sand with Quarry Dust, International Research Journal of Engineering and Technology, vol 5, (pp.4383-4386).

[15] Magda I Mousa, Mohamed G. Mahdy, Ahmed H. AbdelReheem, Akram Z. Yehia, (2015) ,Mechanical Properties of Self-Curing Concrete (SCUC), Housing and Building National Research Centre Journal, vol 54, (pp.565-575).

[16] Mateusz Wyrzykowski, PietroLura, Francesco Pesavento and DariuszGawin,( 2012), Modelling of Water Migration during Internal Curing with Superabsorbent Polymers , journal of materials in civil engineering @ ASCE, vol 24(8), (pp.1006-1016).

[17] MD Akhib K and Vinodh Kumar A, (2018), A Study on Mechanical Properties of Self Curing M65 Grade Concrete by Using Polyethylene Glycol, International Journal of Engineering Science and Computing, vol 8, (pp.1754317546).

[18]Mohammed Bilal and Ambikapathi, (2017), Experimental Study on Internal Curing of High Strength Concrete, International Journal of Engineering Sciences \& Research Technology, (pp.225-260)..

[19] Olawuyi B J, Olusola K O and Babafemi A J, (2012)

Influence of Curing Age and Mix Composition on Compressive Strength of Volcanic Ash Blended Cement Laterized Concret, Civil Engineering Dimension,vol. 14, (pp. 84-91) .

[20]Rahul Dev and Navaneethan R, (2018), Self curing concrete, International Journal of Advance Research,
Ideas and Innovations in technology, vol 4, (pp. 534-541). [21]Remya K M , Shilpa.V S , Dhanusha M, Ashna L Sukumar, Ashnaismayil and Sreerag K, ( 2015), Experimental Study on Strength Characteristics of Self Curing Concrete using Poly Ethylene Glycol and Light Weight Aggregate; International Journal of Research in Advent Technology, (pp. 73-77).

[22]Sachin Julian Francis, Karthik B and Gokulram H, ( 2017), Flexural Behaviour of Self-curing Concrete with Lightweight Aggregate and Polyethylene Glycol, International Journal of Engineering Trends and Technology, vol 47, (pp. 71-77).

[23]Sagar Dushing \& Mehetre A J, (2017), Experimental Investigation of Self Curing Concrete, International Journal of Engineering Sciences \& Research Technology, (pp.752$755)$.

[24]Sampebulu V, (2012), Increase on Strengths of Hot Weather Concrete by Self-Curing of Wet Porous Aggregate, Civil Engineering Dimension,vol. 14, (pp. 92-99).

[25]Saran Kumar J and Dr. Suresh Babu T, (2015), Effect of Self-curing Compound (using peg-400) on Strength and Stress-Strain Behaviour of M25 Concrete Mix,International Journal of Research;vol.3,( pp.215-219).

[26]Saran Kumar Raju K, Janardhan N and Vinodh Kumar A,( 2018), A Study on Mechanical Properties of Self Curing High Strength Concrete by Using Sodium Ligno Sulphonate, International Journal of Engineering Science and Computing, vol 8,(pp.17585-17589).

[27]Selvabharathi G, Anandan V, Dhivya V, Janani J, Jesima S and Krishnakumar P, (2018), Experimental study on Concrete curing agent using Calcium Bentonite powder without curing, International Journal of Latest Engineering and Management Research;,vol 4, (pp.33-37).

[28]Siddiqui Mohammed Junaid, BhadkiSafwan, BodaleAhamad, SayyadKaleemandUldeNuh (2016) An Experimental Investigation on Internally Cured Concrete, International Journal on Recent and Innovation Trends in Computing and Communication, vol 4, (pp.241-244).

[29]Vishnu T and Beena B R, (2016), An Experimental Investigation of Self-Curing Concrete Incorporated with Light Weight Fine Aggregate and Polyethylene Glycol, International Journal for Innovative Research in Science \& Technology, vol 3, (pp.116-122).

[30] Ya Wei, Yaping Xiang and Qianqian Zhang, (2014) Internal Curing Efficiency of PrewettedLWFAson Concrete Humidity and Autogenous Shrinkage Development, Journal of Materials in Civil Engineering @ ASCE, vol 6, (pp.947-954). 